\title{
Body Proportions during Long-Term Growth Hormone Treatment in Girls with Turner Syndrome Participating in a Randomized Dose-Response Trial**
}

\author{
THEO C. J. SAS, WILLEM-JAN M. GERVER, ROB DE BRUIN, THEO STIJNEN, \\ SABINE M. P. F. DE MUINCK KEIZER-SCHRAMA, TIM J. COLE, \\ ARNE VAN TEUNENBROEK, AND STENVERT L. DROP

\begin{abstract}
Department of Pediatrics, Division of Endocrinology (Th.C.J.S., S.M.P.F.M.K.-S., A.T., S.L.S.D.) Sophia Children's Hospital, 3015 GJ Rotterdam, The Netherlands; Academic Hospital Maastricht (W.J.G., R.B.) and the Department of Epidemiology and Biostatistics, Erasmus University (T.S.), Rotterdam, The Netherlands; and the Department of Epidemiology and Public Health, Institute of Child Health (T.J.C.), London, United Kingdom
\end{abstract}

\begin{abstract}
To assess body proportions in girls with Turner syndrome (TS) during long term GH treatment, height, sitting height (SH), hand (Hand) and foot (Foot) lengths, and biacromial (Biac) and biiliacal (Biil) diameters were measured in 68 girls with TS participating in a GH dose-response trial. These previously untreated girls with TS, aged $2-11$ yr, were randomly assigned to 1 of $3 \mathrm{GH}$ dosage groups: group A, $4 \mathrm{IU} / \mathrm{m}^{2} \cdot$ day; group B, first year 4 and thereafter $6 \mathrm{IU} / \mathrm{m}^{2} \cdot$ day; group C, first year 4 , second year 6 , and thereafter $8 \mathrm{IU} / \mathrm{m}^{2} \cdot$ day. Seven-year data were evaluated to assess the effect of GH treatment on body proportions during childhood. In addition, data from all girls who had reached adult height were evaluated to determine the effect on the adult body proportions. All results were adjusted for age and sex and expressed as SD scores using reference values of healthy Dutch girls. To describe the proportions of SH, Hand, Foot, Biac, and Biil to height, these values were adjusted for the SD score of height and were expressed as shape values, using the formula, e.g. for SH: shape $\mathrm{SH}=$ (SH SD score - height SD score $) / \sqrt{ }(2-2 \times$ correlation coefficient between $\mathrm{SH}$ and height in the reference population). Furthermore, SD scores using references of untreated girls with TS were calculated for height and SH. Values less than -2 or more than +2 were considered outside the normal range.

At baseline, the shape values of all measurements were significantly higher than zero, but most mean shape values were still within
\end{abstract}

the normal range. Seven-year data of 64 girls and adult height data of 32 girls showed that an increase in height was accompanied by an even higher increase in Foot, resulting in mean SD scores above zero and shape values of +2 and higher. The increase in the shape value of Foot was significantly higher in groups B and C compared to that in group A after $7 \mathrm{yr}$ of $\mathrm{GH}$ treatment, but there were no significant differences between the GH dosage groups in the girls who had reached adult height. The shape values of SH had decreased to values closer to zero after reaching adult height, especially in group A. A similar pattern in the relationship of $\mathrm{SH}$ to height was seen using references of girls with TS. No significant changes in the other proportions were found after reaching adult height.

In conclusion, on the average, untreated girls with TS have relatively large trunk, hands, and feet, and broad shoulders and pelvis compared to height. The increase in height after long term GH treatment is accompanied by an even higher increase in Foot and a moderate improvement of the disproportion between height and SH. Recently published reference data from untreated adults with TS and the results of a different patient group receiving a comparable GH dosage suggest that the disproportionate growth of feet has to be considered a part of the natural development in TS, but might be influenced by higher GH dosages. The development of large feet can play a role in the decision of the girl to discontinue GH treatment in the last phase of growth. (JClin Endocrinol Metab 84: 4622-4628, 1999)
G ROWTH FAILURE and subsequently short adult stature are two of the main features in Turner syndrome (TS) $(1,2)$. Although these girls are not clearly GH deficient (3), GH administration accelerates growth in a dose-dependent way (4-6). In addition, recent reports reported a considerable increase in adult height in girls who started GH treatment at a relatively young age (7-9).

The general clinical impression of body proportions of untreated girls with TS is that these girls have a more coarse and stocky figure compared to healthy girls. This is confirmed by earlier studies describing relatively short lower

Received July 14, 1999. Revision received September 17, 1999. Accepted September 20, 1999.

Address all correspondence and requests for reprints to: Theo C. J. Sas, M.D., Division of Endocrinology, Sophia Children's Hospital, Dr. Molewaterplein 60, 3015 GJ Rotterdam, The Netherlands.

* This work was supported by Novo Nordisk A/S (Bagsvaerd, Denmark). extremities and relatively broad shoulders and pelvis (1012). Little is known about the effects of supraphysiological $\mathrm{GH}$ dosages given for a long time during childhood. The most remarkable reported changes in body proportions in TS after 2 yr of GH treatment were an increase in pelvic width and an increased length and breadth of hands and feet compared to the increase in height $(10,13)$. Four-year data on height and sitting height $(\mathrm{SH})$ were described by Rongen $e t$ al., demonstrating no change in proportion (14).

To determine the body proportions before, during, and after long term GH treatment, we measured height, $\mathrm{SH}$, hand length (Hand), foot length (Foot), biacromial diameter (Biac), and biiliacal diameter (Biil) in 68 girls with TS participating in a randomized dose-response study. The effect on height was described previously (15). We now report body proportions during childhood, comparing 7-yr data from $3 \mathrm{GH}$ dosage groups. Data from all girls who have reached adult height have been evaluated as well. 


\section{Subjects and Methods}

Sixty-eight previously untreated girls with TS were enrolled in a multicenter GH dose-response study. The diagnosis was confirmed by lymphocyte chromosomal analysis. Inclusion criteria were a chronological age between 2-11 yr, height below the 50th percentile for healthy Dutch girls (16), and normal thyroid function. Exclusion criteria were associated endocrine and / or metabolic disorders, growth failure caused by other disorders or emotional deprivation, hydrocephalus, previous use of drugs that could interfere with GH treatment, and spontaneous puberty (17). Written informed consent was obtained from the girls and their parents or custodians. The study protocol was approved by the ethics committee of each participating center.

Sixty-eight girls were approached, and after the randomization all girls started GH treatment. After stratification for chronological age and height SD score for chronological age girls were randomly assigned to the following groups: group $\mathrm{A}(\mathrm{n}=23)$, receiving $4 \mathrm{IU} / \mathrm{m}^{2}$ body surface day (equivalent to $0.045 \mathrm{mg} / \mathrm{kg}$ ); group B $(\mathrm{n}=23)$, receiving 4 $\mathrm{IU} / \mathrm{m}^{2} \cdot$ day in the first year, followed by $6 \mathrm{IU} / \mathrm{m}^{2} \cdot$ day; and group $\mathrm{C}(\mathrm{n}=$ 22), receiving $4 \mathrm{IU} / \mathrm{m}^{2} \cdot$ day in the first year, $6 \mathrm{IU} / \mathrm{m}^{2}$.day in the second year, and thereafter $8 \mathrm{IU} / \mathrm{m}^{2}$.day.

Biosynthetic human GH (Norditropin, Novo Nordisk A/S, Bagsvaerd, Denmark) was given sc once daily at bedtime using a pen injection system. Every 3 months the total GH dose was adjusted to the calculated body surface. According to study protocol, treatment was stopped when subjects had grown less than $1 \mathrm{~cm}$ over 6 months. After the first $4 \mathrm{yr}$ of the study period, girls started estrogen therapy when they had reached the age of $12 \mathrm{yr}$. In the first $2 \mathrm{yr}$ of estrogen therapy, the girls received $5 \mu \mathrm{g} 17 \beta$-estradiol $/ \mathrm{kg} \mathrm{BW} \cdot$ day, in the third year they received $7.5 \mu \mathrm{g} / \mathrm{kg} \cdot$ day, and thereafter they were given $10 \mu \mathrm{g} / \mathrm{kg} \cdot$ day.

Height, $\mathrm{SH}$, Hand (left), Foot (left), Biac, and Biil were measured at baseline and subsequently every 6 months by two trained observers. Measurements were taken according to the procedure of Cameron (18). Height and SH were obtained using a Harpenden stadiometer and SH table. The other measurements were taken with the Harpenden anthropometer. Two measurements per visit were made, and the mean was used for the analysis. The results of each measurement were adjusted for age and sex and expressed as a SD score. When GH treatment was stopped, the last available measurements at discontinuation of GH treatment were considered the definite values, assuming that no change in body proportions will take place after stopping $\mathrm{GH}$ treatment. For the evaluation of body proportions in the girls after reaching adult height, the reference values at the age of 18 yr were used for calculating the SD scores. The data of the Oosterwolde Study were used as references for healthy Dutch girls (19). This reference population consisted of 1093 Dutch girls, ranging from birth to $18 \mathrm{yr}$ of age. To calculate sD scores, data from the reference population were transformed using the LMS method $(20,21)$. This method transforms the reference data at each age to a normal distribution. In addition, the SD scores of the measurements of SH, Hand, Foot, Biac, and Biil were adjusted for the height SD score and expressed as the shape value. The shape value, in this example defined as the SH SD score adjusted for the height SD score, was calculated using the formula $(10,22)$ : shape $\mathrm{SH}=(\mathrm{SH}$ sD score - height SD score $) / V(2-2 r)$, in which $r$ is the correlation coefficient between height and $\mathrm{SH}$ in the reference population. Values less than -2 or more than +2 were considered outside the normal range.

Unfortunately, no reference values from untreated girls with TS were available, except for height (Dutch-Swedish-Danish Turner references) (2) and SH (Dutch Turner references) (12). Because the reference populations for height and SH were not totally identical, and the correlation coefficient between height and SH in girls with TS was not known, only SD scores of both measurements were calculated using the reported means and SDs per yr. For the evaluation of body proportions in the girls after reaching adult height, the Turner reference values at maximum ages of 21 and 23 yr were used for calculating the Turner SD scores of height and $\mathrm{SH}$, respectively. Seven girls were of non-Caucasian origin ( 3 in group A, 3 in group B, and 1 in group C). Although reference values for body proportions of non-Caucasian girls might be somewhat different compared to our Caucasian references, all girls were included in the statistical analysis. Pubertal stages were assessed according to the method of Tanner (17).

Results are expressed as the mean (SD), unless indicated otherwise. At baseline, after $7 \mathrm{yr}$, and after reaching adult height, SD scores and shape values were compared with zero using Student's one-sample $t$ tests. SD scores or shape values after $7 \mathrm{yr}$ of GH treatment or after reaching adult height were compared to baseline using paired Student's $t$ tests. Differences in change in shape values between the GH dosage groups were first tested by a linear trend test to assess a possible dosedependent effect. In case of a significant result, this was followed by comparisons with Student's two-sample $t$ tests. An intention to treat analysis was performed based on all available data. $P<0.05$ was considered significant.

\section{Results}

The trial started in 1989. In October of 1997, all girls had been followed for $7 \mathrm{yr}$. At the end of August 1998, 32 patients had discontinued $\mathrm{GH}$ treatment. In each group 1girl dropped out of the study long before reaching adult height for the following reasons: noncompliance, presumed increase in muscle mass and decline in school performance, and desire to initiate estrogen therapy before the fourth year of $\mathrm{GH}$ treatment. In another girl in group B no measurements of body proportions were available after $4 \mathrm{yr}$ of treatment. Therefore, analysis of body proportions during long term $\mathrm{GH}$ treatment was not possible in these four girls. Table 1 lists the baseline clinical data of the remaining 64 girls as well as those of the 32 girls who had discontinued GH treatment after reaching (near) adult height. The 3 groups of patients had similar initial characteristics.

\section{7-yr evaluation}

Figure 1 shows the SD scores of the measurements at baseline and during $7 \mathrm{yr}$ of $\mathrm{GH}$ treatment in groups A, B, and C, respectively. At the start of GH treatment, all mean SD scores were significantly lower than zero, indicating stunted growth in several body parts. However, the baseline SD score of height was lower than the SD scores of the other measurements. After $7 \mathrm{yr}$ of $\mathrm{GH}$ treatment all SD scores had increased significantly compared to baseline. The SD scores of height, SH, Biac, and Biil showed an increase, especially in the first $4 \mathrm{yr}$ of treatment, whereas the SD scores of Hand and Foot demonstrated a sustained increase throughout the entire study period up to values higher than zero in the higher $\mathrm{GH}$ dosage groups.

The SD scores of height and SH using the Turner references are presented in Fig. 2. At the start of treatment, height and $\mathrm{SH}$ were not different from those in Turner controls, except for $\mathrm{SH}$ in group B. After $7 \mathrm{yr}$, height and $\mathrm{SH}$ showed similar

TABLE 1. Mean (SD) baseline data for each treatment group.

\begin{tabular}{lccc}
\hline & Group A & Group B & Group C \\
\hline Total group of girls & & & \\
No. of girls & 22 & 21 & 21 \\
Chronological age (yr) & $6.1(2.1)$ & $6.7(2.5)$ & $6.5(2.4)$ \\
Ht SD score & $-2.9(0.9)$ & $-2.8(0.8)$ & $-2.7(1.0)$ \\
Karyotype & $18(82 \%)$ & $20(95 \%)$ & $16(76 \%)$ \\
$\quad 45, X$ & $4(18 \%)$ & $1(5 \%)$ & $5(24 \%)$ \\
$\quad$ other & 10 & 10 & 12 \\
32 girls who had reached (near) adult height & \\
No. of girls & $10(0.9)$ & $8.6(1.6)$ & $8.1(1.4)$ \\
Chronological age $(\mathrm{yr})$ & $7.9(0.9)$ & $-3.0(0.7)$ & $-3.0(0.7)$ \\
Ht SD score & $-2.9(1.0)$ &
\end{tabular}

Karyotype (45,X; other) is expressed as the number (percentage) of patients. 

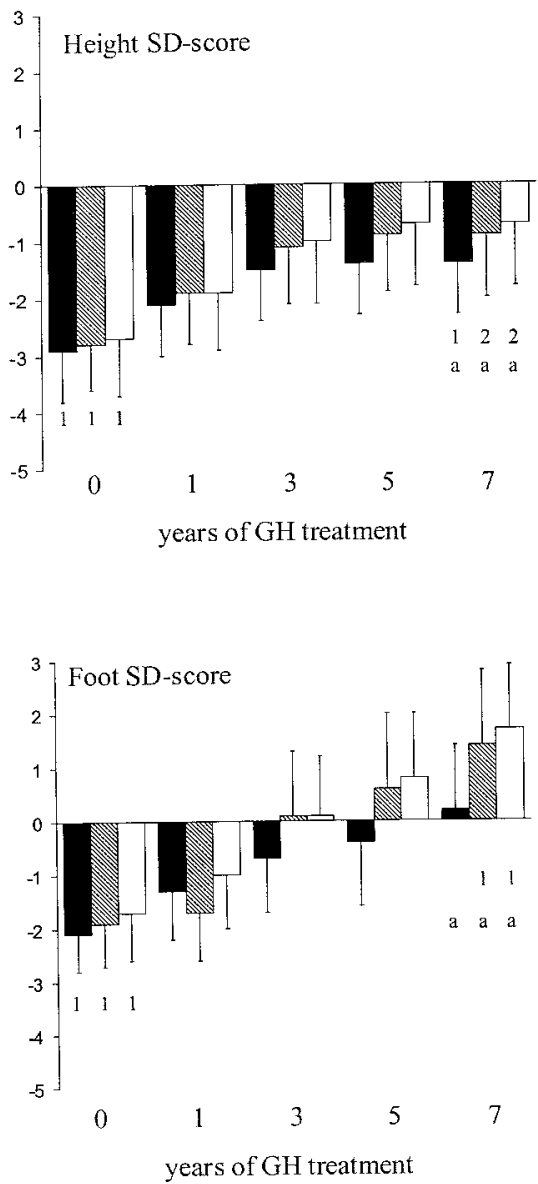
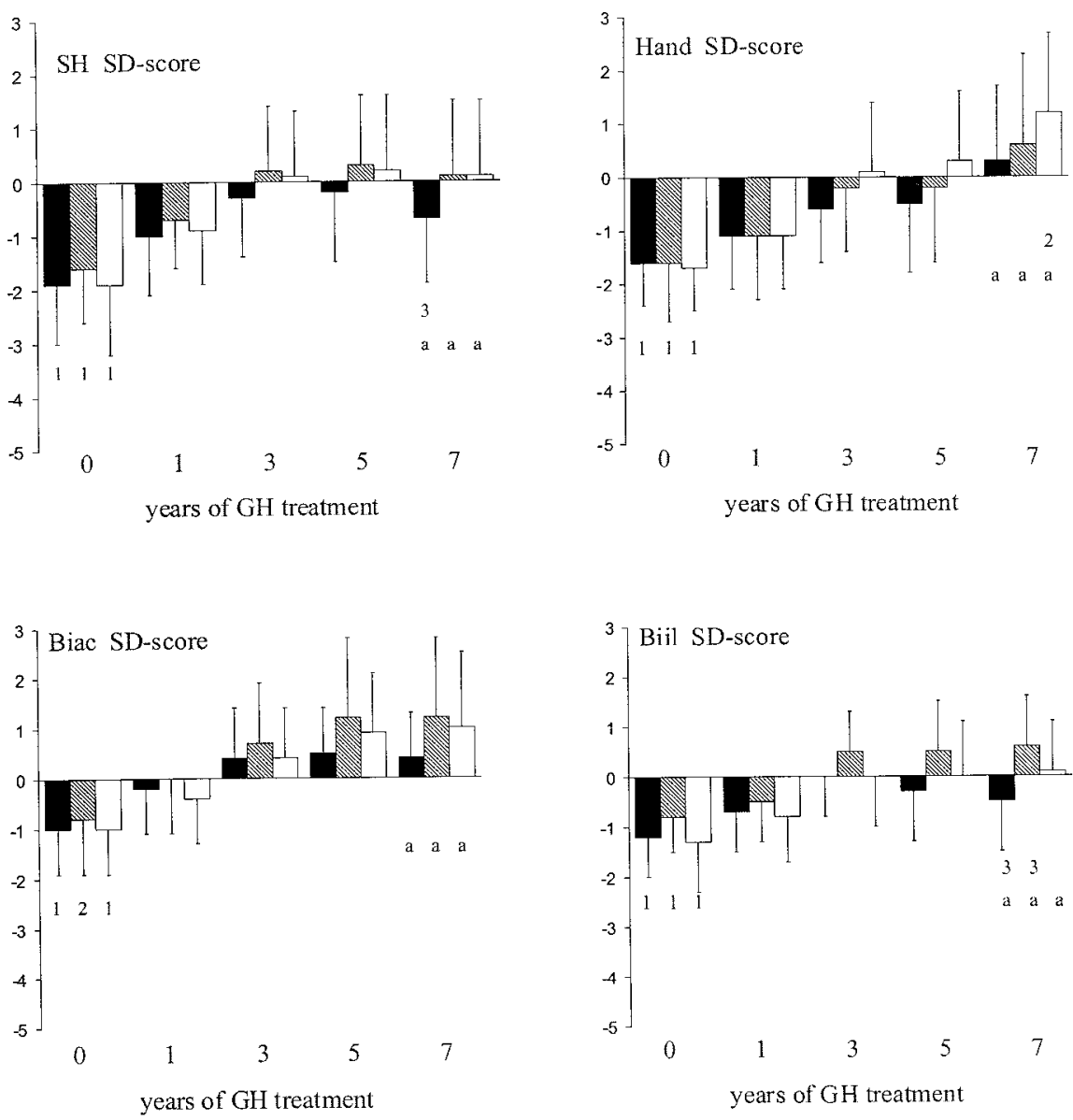

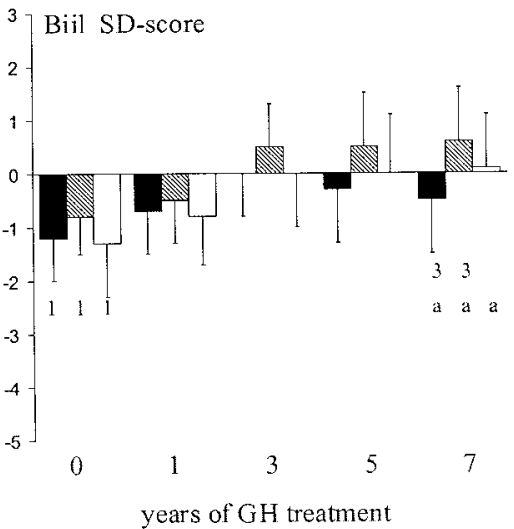

FIG. 1. Mean (SD) SD scores using reference values from healthy Dutch girls at baseline and during 7 yr of GH treatment in groups A (black bars), B (gray bars), and C (white bars), respectively. Significant differences from zero $(1, P<0.001 ; 2, P<0.005 ; 3, P<0.05)$ and significant changes from baseline to $7 \mathrm{yr}$ of $\mathrm{GH}$ treatment $(\mathrm{a}, P<0.001)$ are indicated.

increases, suggesting no obvious change in body proportion between height and $\mathrm{SH}$.

Figure 3 shows the shape values at baseline and during 7 yr of treatment for groups A, B, and C. At the start of the treatment all mean shape values were significantly higher than zero, indicating a relatively large trunk, relatively large hands and feet, and relatively broad shoulders and pelvis compared to height. However, most shape values were within the normal range. The shape values of $\mathrm{SH}$ and Biac had not significantly changed over the $7 \mathrm{yr}$, whereas the shape value of Biil had significantly decreased. The mean shape values of Hand showed a decrease in the first years of the study followed by an increase up to values around +2 ; however, they were only statistically significant from baseline in group $\mathrm{C}$. The shape values of Foot increased significantly during treatment up to values +2 or greater in all three GH dosage groups. Only the increase in shape value of Foot was significantly higher in groups B and C compared to that in group $\mathrm{A}$, without a significant difference between groups $\mathrm{B}$ and $\mathrm{C}$.

Girls who remained prepubertal throughout the entire study period $(n=24)$ showed similar patterns in shape values as the whole study group (data not shown).

\section{Body proportions after reaching adult height}

Thirty-two patients (groups A, B, and C; $\mathrm{n}=10,10$, and 12 , respectively) have discontinued $\mathrm{GH}$ treatment after a mean duration of treatment of $7.3 \mathrm{yr}$ (1.1) (range, 5.0-8.5 yr). Twenty girls had discontinued GH treatment because of a height velocity less than $1 \mathrm{~cm}$ over 6 months, and 12 girls stopped GH treatment in the last phase of growth because they were satisfied with their attained height.

The baseline clinical data of these 32 girls were, except for age, comparable with the baseline data of the total group of 64 girls (Table 1). At the last measurements, the mean (SD) age was 15.6 (0.7) yr in group A, 15.2 (1.3) yr in group B, and 15.2 (0.9) yr in group C. Although, the duration of the GH treatment (from baseline to the last measurement) seemed to be shorter in groups B [6.7 (1.3)] and C [7.1 (1.2)] than in group A [7.6 (0.7)], the linear trend test showed no significant dosedependent effect.

Table 2 shows the SD scores and shape values at the start of treatment and at discontinuation of GH treatment. Baseline values of these 32 girls were similar to those of the total group of 64 girls. Except for the SD score of $\mathrm{SH}$ in group $\mathrm{A}$, all SD scores had significantly increased compared to baseline. The largest increase in SD scores was seen in Hand and 

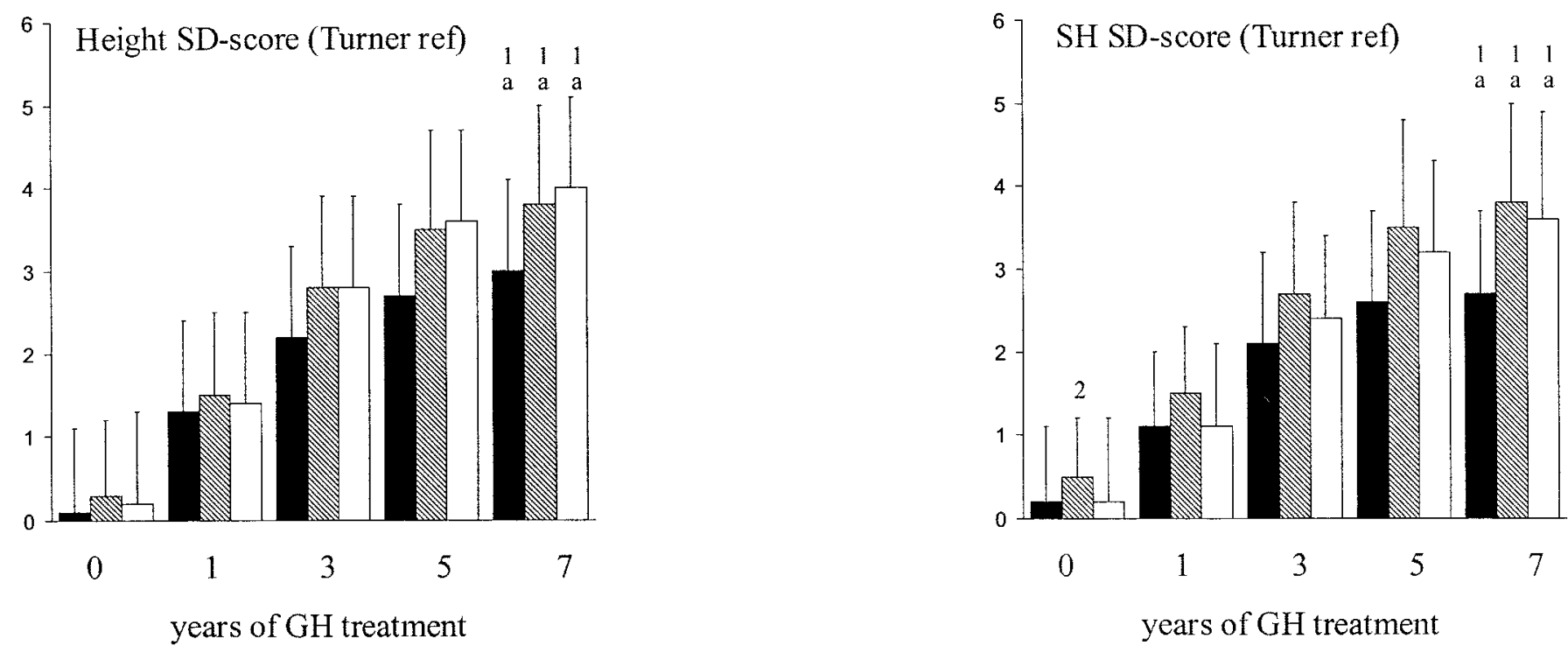

FIG. 2. Mean (SD) SD scores of height and SH using the Turner references at baseline and during 7 yr of GH treatment in groups A (black bars), B (gray bars), and C (white bars), respectively. Significant differences from zero $(1, P<0.001)$ and significant changes from baseline to 7 yr of $\mathrm{GH}$ treatment $(\mathrm{a}, P<0.001)$ are indicated.

Foot. In group C, Foot had increased to a mean value significantly higher than that in healthy women. The shape values of Biac and Biil showed no change compared to baseline, whereas the shape value of $\mathrm{SH}$ had significantly decreased. The decrease in the shape value of $\mathrm{SH}$ was significant less in groups $B$ and $C$ than in group $A$. The mean shape values of Hand deviated more toward abnormal high values; however, these changes were not statistically significant. The shape value of Foot had increased significantly to values outside the normal range, without significant differences between the GH dosage groups.

The SD scores of height using the Turner references had significantly increased by $1.7(0.5)$ in group A, $1.9(0.6)$ in group $\mathrm{B}$, and $2.2(0.7)$ in group $\mathrm{C}$ compared to baseline $(P<$ $0.001)$. The increase in the sD score of SH using Turner references increased by $0.6(0.5)$ in group A, $0.9(0.4)$ in group $\mathrm{B}$, and $1.3(0.7)$ in group $\mathrm{C}$ compared to baseline $(P=0.004$ for group $\mathrm{A} ; P<0.001$ for groups $B$ and $C$ ). Thus, the increase in the Turner SD score for height seems to be higher than that in the SD score for SH.

\section{Discussion}

The present study showed that untreated girls with TS, between 2-11 yr of age, are short and have smaller hands and feet and narrow shoulders and pelvis compared to healthy peers. As height is more affected than other parts of the body, untreated girls have, on the average, a relatively large trunk, relatively large hands and feet, and relatively broad shoulders and pelvis compared to height. Most shape values, however, were within the normal range. Our data are in line with the results reported by Gerver et al., describing higher mean shape values in somewhat older girls $(6-19 \mathrm{yr})$ with TS (10). Zellner et al. demonstrated higher SD scores of Hand and Foot than of height, indicating relatively large hands and feet (13). Rongen et al. reported that especially younger girls with TS have relatively short legs compared to trunk height (12).
During GH treatment all measured parts of the body increased in size to values close to those in healthy peers or even higher. The 7-yr data showed that the increase in SH and Biac was comparable with that in height, resulting in no change in shape values. Although we do not have shape values for SH based on Turner references, our 7-yr Turner SD scores also suggest no change in the proportion of $\mathrm{SH}$ to height. The shape value of the Biil had decreased during the $7 \mathrm{yr}$ to values more appropriate for height. Hand and Foot showed a sustained increase in size throughout the entire study period, resulting in mean SD scores above zero and shape values approximately +2 or higher. Only the increase in the shape value of Foot was dose dependent. Other studies in girls with TS also reported a higher increase in the SD scores of hand and foot than in that of height after $2 \mathrm{yr}$ of GH treatment $(10,13)$. Rongen et al. demonstrated, as we did, no change in the preexisting disproportion between height and $\mathrm{SH}$ during childhood after 4 ys of GH treatment (14). However, the biggest change in body proportions in the study of Gerver et al. was the increased Biil compared to height after $2 \mathrm{yr}$ of GH treatment (10). In our study, the shape value of Biil decreased during $7 \mathrm{yr}$ of GH treatment and was not changed in the subgroup of girls who had reached adult height. The discrepancy between the previously published data and our data concerning Biil compared to height may be caused by the good catch-up in height and the lesser increase in Biil. Compared to the other measurements, the measurement of Biil is higher influenced by the increase in body fat, which is seen especially in adolescents and adults with TS.

Thirty-two girls had reached their adult stature after long term GH treatment. For the present study, we made the assumption that no change in body proportions will take place after stopping GH treatment. Our clinical impression is that only some additional millimeters to a centimeter in height can be achieved in the years after discontinuation of 

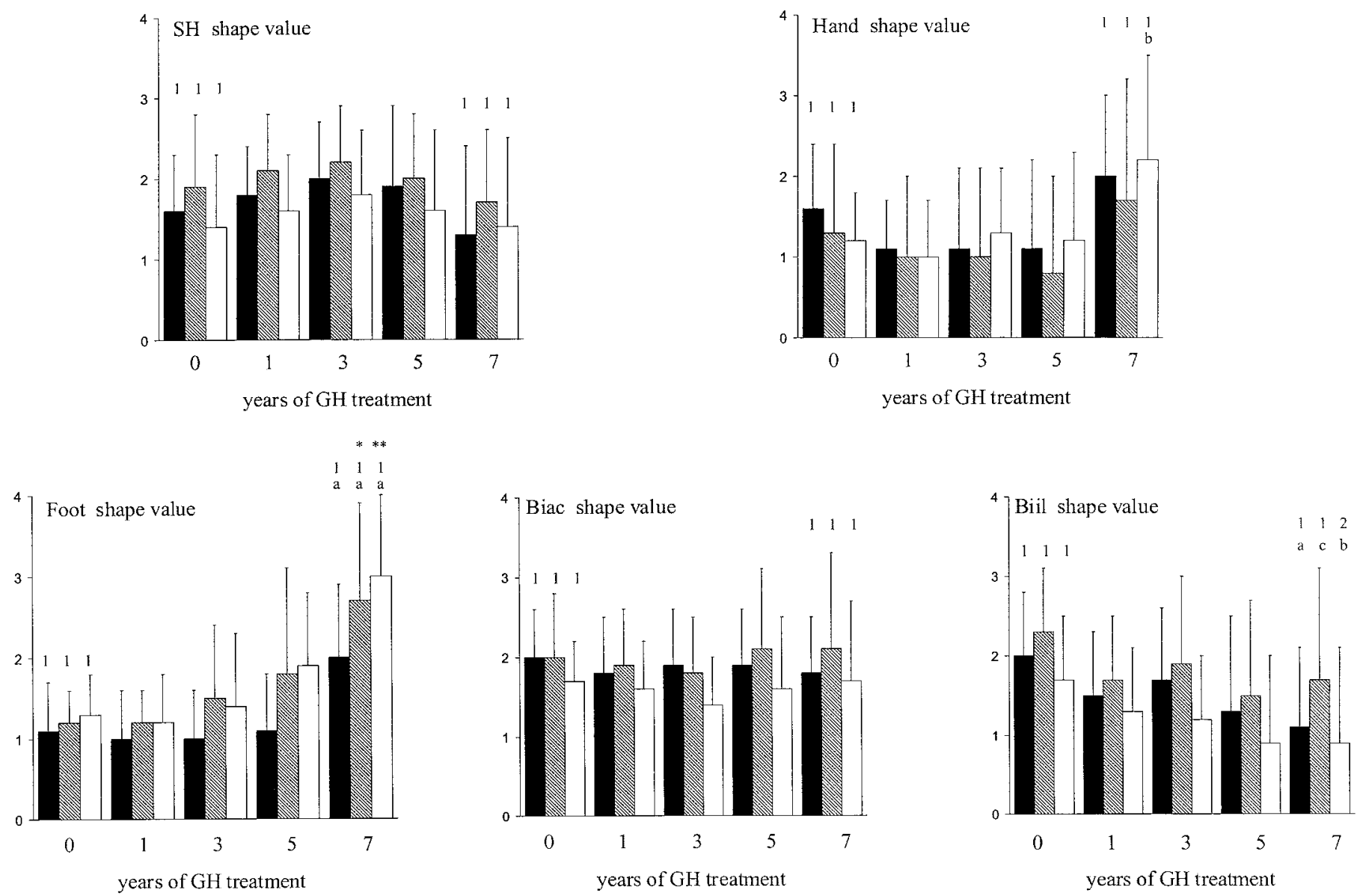

FIG. 3. Mean (SD) shape values at baseline and during $7 \mathrm{yr}$ of treatment for groups A (black bars), B (gray bars), and C (white bars), respectively. Significantly differences from zero $(1, P<0.001 ; 2, P<0.005)$ and significant changes from baseline to $7 \mathrm{yr}$ of GH treatment $(\mathrm{a}, P<0.001$; b, $P<0.005 ; \mathrm{c}, P<0.05)$ are indicated. Significant differences in the changes in shape value from baseline to $7 \mathrm{yr}$ of GH treatment in this GH dosage group compared to group A were also indicated (*, $P<0.05$; **, $P<0.005$ ).

treatment after reaching (near) final height. However, we assumed that the possible additional millimeters in height will be accompanied by a similar increase in size of other parts of the body after stopping GH treatment. Preliminary data for older girls with TS obtained by our group seem to confirm this assumption; however, follow-up of the girls in the present study is required to substantiate this. The data from the 32 girls showed no change in shape values of Biac and Biil. Although the shape value of Hand had deviated more from normal compared to baseline, the change was not significant. In contrast, Foot had increased to mean values equal to or higher than the mean value for healthy women and shape values outside the normal range. However, no significant differences between the GH dosage groups were found. The shape value of $\mathrm{SH}$ showed a decrease to values close to zero, especially in group A. The SD scores for height and $\mathrm{SH}$ using Turner references showed the same pattern: a higher increase in height than in SH. Thus, in the girls who had reached adult height after long term GH treatment, the disproportion between $\mathrm{SH}$ and height had improved, but the proportion of Foot to height had worsened.

The cause and mechanism of the change in body proportions after long term GH treatment in girls with TS are not clear-cut. In our study, girls in group A received the usual
GH dose, but higher $\mathrm{GH}$ doses were given in groups B and C. The 7-yr increase in shape value of Foot was dose dependent, suggesting a GH-induced abnormality. In adults, excessive GH secretion can lead to acromegalic features, including big hands and feet, which are caused by thickening of the bone and surrounding soft tissue. Less is known about the effects of high GH levels during childhood. Although we did not include systematic radiographic measurements of bone length and soft tissue in our study, we saw no obvious soft tissue thickening on the standardized x-rays of the hand. This suggests that in girls with TS the increase in the size of the hands is caused by longitudinal growth of bone and does not seem to be part of the acromegalic changes. In addition, it has been reported that high GH levels in children during the growth phase (gigantism; most common cause is an autonomously functioning pituitary adenoma) result in proportional growth in length and width of the bones (23). As in most other studies, we did not include a randomized control group receiving no GH treatment until adult height. Unfortunately, no reference values for TS were available for Hand, Foot, Biac, and Biil during the growth phase. Therefore, we do not know the natural development of those body proportions in untreated girls with TS during childhood. However, recent reference values were reported for adult 
TABLE 2. Mean (SD) SD scores and shape values at baseline and after reaching adult height in 32 girls who have reached adult height

\begin{tabular}{|c|c|c|c|c|c|c|}
\hline & \multicolumn{3}{|c|}{ At baseline } & \multicolumn{3}{|c|}{ At stop GH treatment } \\
\hline & Group A & Group B & Group C & Group A & Group B & Group C \\
\hline \multicolumn{7}{|l|}{ SD score } \\
\hline $\mathrm{H}$ & $-2.9(1.0)^{a}$ & $-3.0(0.7)^{a}$ & $-3.0(0.7)^{a}$ & $-2.0(1.0)^{a, b}$ & $-1.8(1.0)^{a, b}$ & $-1.6(0.9)^{a, b}$ \\
\hline SH & $-1.9(1.3)^{c}$ & $-1.6(0.8)^{a}$ & $-2.0(1.2)^{a}$ & $-2.3(1.5)^{c}$ & $-1.1(1.2)^{d, e}$ & $-1.2(1.4)^{d, e}$ \\
\hline Hand & $-1.8(0.9)^{a}$ & $-2.0(1.1)^{a}$ & $-1.9(0.8)^{a}$ & $-0.1(1.9)^{f}$ & $-0.6(1.9)^{f}$ & $0.3(2.2)^{f}$ \\
\hline Foot & $-2.1(0.8)^{a}$ & $-2.2(0.7)^{a}$ & $-1.9(0.7)^{a}$ & $0.2(1.4)^{b}$ & $0.9(1.4)^{b}$ & $1.4(1.3)^{b, c}$ \\
\hline Biac & $-1.3(1.1)^{c}$ & $-1.0(1.0)^{d}$ & $-1.2(0.9)^{c}$ & $-0.2(1.1)^{b}$ & $0.0(1.3)^{e}$ & $0.2(1.3)^{f}$ \\
\hline Biil & $-1.4(1.0)^{c}$ & $-0.8(0.7)^{c}$ & $-1.4(0.8)^{a}$ & $-0.4(0.5)^{f}$ & $0.4(0.6)^{d, f}$ & $0.0(1.0)^{f}$ \\
\hline \multicolumn{7}{|c|}{ Shape value } \\
\hline $\mathrm{SH}$ & $1.7(0.6)^{a}$ & $2.4(0.7)^{a}$ & $1.6(1.0)^{a}$ & $-0.4(1.1)^{b}$ & $1.2(1.2)^{d, f, g}$ & $0.7(1.4)^{e, g}$ \\
\hline Hand & $1.4(0.5)^{a}$ & $1.2(1.2)^{d}$ & $1.3(0.6)^{a}$ & $2.2(1.2)^{a}$ & $1.5(1.5)^{d}$ & $2.2(1.8)^{c}$ \\
\hline Foot & $1.0(0.6)^{c}$ & $1.0(0.3)^{a}$ & $1.3(0.5)^{a}$ & $2.7(1.0)^{a, b}$ & $3.2(0.9)^{a, b}$ & $3.6(1.0)^{a, b}$ \\
\hline Biac & $1.6(0.5)^{a}$ & $2.0(0.8)^{a}$ & $1.8(0.3)^{a}$ & $1.8(0.9)^{a}$ & $1.8(1.0)^{a}$ & $1.8(1.2)^{a}$ \\
\hline Biil & $1.7(0.9)^{a}$ & $2.5(0.7)^{a}$ & $1.7(0.9)^{a}$ & $1.9(0.9)^{a}$ & $2.6(1.0)^{a}$ & $1.8(1.2)^{a}$ \\
\hline
\end{tabular}

The differences between the GH dosage groups were only tested for the change in shape values.

${ }^{a} P<0.001$ vs. zero.

${ }^{b} P<0.001$ vs. baseline.

${ }^{c} P<0.005$ vs. zero.

${ }^{d} P<0.05$ vs. zero.

${ }^{e} P<0.05$ vs. baseline.

${ }^{f} P<0.005$ vs. baseline.

${ }^{g} P<0.05$ change in shape value from baseline to adulthood compared to that of group A.

women with TS, who had received no GH therapy in childhood (24). To compare those data with ours, we calculated the mean shape values from the SD scores of that study, because the same reference population was used as in our study. It was shown that untreated adult women with TS have no disproportion between height and $\mathrm{SH}$, but shape values of Hand were even higher than those in our 32 girls who had reached adult height. The mean shape value of Foot in these women was as high as that in group A, but was lower than those in groups B and C in our analysis of adult data. The shape values for Biac and Biil were considerably higher than our adult shape values. These reference data suggest that the decrease in shape $\mathrm{SH}$ and the increase in shape values for Hand and Feet found in our study are partly due to the natural development of these body proportions in girls with TS. As observed in forms of skeletal dysplasia, body proportions may change during childhood. One might speculate that GH exaggerates this naturally occurring disproportionate growth in girls with TS while they reach a normal height. Remarkably, our data from a different patient group receiving $6 \mathrm{IU} \mathrm{GH} / \mathrm{m}^{2} \cdot$ day showed no abnormal growth of hands and feet (Sas, T. C., W. J. Gerver, R. de Bruin, et al., submitted for publication). Because the increments in shape values of Hand and Foot appeared mainly after the fourth year, estrogen therapy was thought to be one of the causes of the abnormal development of Hand and Foot. However, the same pattern was seen in the girls without pubertal signs and estrogen therapy throughout the study. Therefore, the changes in body proportions could not be attributed to puberty or estrogen therapy.

As described in previous reports, long term GH treatment results in a height within the normal range in most girls with TS $(7,15)$. In the present study we showed that the increase in height is accompanied by abnormal growth of the feet, resulting in relatively large feet for height as well as for age. Especially in the last phase of growth, some girls in our study complained about big feet. The possibility of additional foot growth may have influenced their decision to discontinue $\mathrm{GH}$ treatment before adult height was reached.

In conclusion, girls with TS have, on the average, a relatively large trunk, hands, and feet, and broad shoulders and pelvis compared to height. The increase in height after long term GH treatment is accompanied by an even greater increase in the size of the feet and a moderate improvement of the disproportion between height and SH. Recent published reference data for adults with TS and results of a different GH-treated patient group suggest that the disproportionate growth of feet is part of the natural development in TS, but might be influenced by higher GH dosages.

\section{Acknowledgment}

Mrs. Ingrid van Slobbe, research -nurse, is gratefully acknowledged for her assistance.

\section{References}

1. Ranke MB, Pflüger H, Rosendahl W, et al. 1983 Turner syndrome: spontaneous growth in 150 cases and review of the literature. Eur J Pediatr. 141:81-88.

2. Karlberg J, Albertsson-Wikland K, Naeraa RW, Rongen-Westerlaken C, Wit JM. 1993 Reference values for spontaneous growth in Turner girls and its use in estimating treatment effects. In: Hibi I, Takano K, eds. Basic and clinical approach to Turner syndrome. Amsterdam: Elsevier Science; 83-92.

3. Wit JM, Massarano AA, Kamp GA, et al. 1992 Growth hormone (GH) secretion in Turner girls as determined by time series analysis. Acta Endocrinol (Copenh). 127:7-12.

4. Stahnke N, Stubbe P, Attanasio A, Reinhardt D, Partsch CJ, Sippell WG. 1993 GH therapy alone or together with oxandrolone in 212 patients with Turner syndrome (TS): the German experience. In: Hibi I, Takano K, eds. Basic and clinical approach to Turner syndrome, Amsterdam: Elsevier Science; 315-322.

5. Teunenbroek van A, Muinck Keizer-Schrama de SMPF, Stijnen T, et al. 1996 Yearly stepwise increments of the growth hormone dose results in a better growth response after four years in girls with Turner syndrome. J Clin Endocrinol Metab. 81:4013-4021.

6. Carel JC, Mathivon L, Gendrel C, Ducret JP, Chaussain JL. 1998 Near normalization of final height with adapted doses of growth hormone in Turner's syndrome. J Clin Endocrinol Metab. 83:1462-1466.

7. Rosenfeld RG, Attie KM, Frane J, et al. 1998 Growth hormone therapy of Turner's syndrome: Beneficial effect on adult height. J Pediatr. 132:319-324.

8. Haeusler G, Schmitt K, Blümel P, Plöchl E, Waldhör T, Frisch H. 1996 Growth hormone in combination with anabolic steroids in patients with Turner syndrome: effect on bone maturation and final height. Acta Paediatr. 85:1408-1414 
9. Nilsson KO, Albertsson-Wikland K, Alm J, et al. 1996 Improved final height in girls with Turner's syndrome treated with growth hormone and oxandrolone. J Clin Endocrinol Metab. 81:635-40.

10. Gerver WJM, Drayer NM, van Es A. 1992 Does growth hormone treatment of patients with Turner's syndrome cause an abnormal body shape? Acta Paediatr. 81:691-694.

11. Neufeld ND, Lippe BM, Kaplan SA. 1978 Disproportionate growth of the lower extremities. Am J Dis Child. 132:296-298.

12. Rongen-Westerlaken C, Rikken B, Vastrick P. 1993 Body proportions in individuals with Turner syndrome. Eur J Pediatr. 152:813-817.

13. Zellner K, Keller E, Kromeyer K, Jaeger U. 1997 Acromegaloidal changes in Ullrich-Turner syndrome after treatment with growth hormone. Acta Med Auxol. 29:125- 133

14. Rongen-Westerlaken C, Nienhuis HE, Wit JM, et al. 1993 The effect of four years of growth hormone therapy on body stature and proportions in patients with Turner syndrome. In: Hibi I, Takano K, eds. Basic and clinical approach to Turner syndrome. Amsterdam: Elsevier Science; 83-92.

15. Sas TC, Muinck Keizer-Schrama de SMPF, Stijnen T, et al. Normalization of height in girls with Turner's syndrome after long-term growth hormone treatment: results of a randomized dose-response trial. In press.
16. Roede MJ, Wieringen JC. 1985 Growth diagrams 1980. Netherlands third nationwide survey. Tijdschr Soc Gezondh. 63(Suppl):1-34.

17. Tanner JM, Whitehouse R. 1976 Clinical longitudinal standards for height weight, height velocity, weight velocity and stages of puberty. Arch Dis Child. 51:170-179.

18. Cameron N. 1987 The methods of auxological anthropometry. In: Falkner F, Tanner JM eds. Human growth, vol 2. London: Tindall.

19. Gerver WJM, de Bruin R. 1996 Paediatric morphometrics, a reference manual. Utrecht: Bunge.

20. Cole TJ. 1989 The British, American NCHS, and Dutch weight standards compared using the LMS method. Am J Hum Biol. 1:397-408.

21. Cole TJ. 1989 Using the LMS method to measure skewness in the NCHS and Dutch National height standards. Ann Hum Biol. 16:407-419.

22. Tanner JM. 1952 The assessment of growth and development in children. Arch Dis Child. 27:10-33.

23. Chew FS. 1991 Radiologic manifestations in the musculoskeletal system of miscellaneous endocrine disorders. Radiol Clin North Am. 29:135-147.

24. Gravholt CH, Naeraa RW. 1997 Reference values for body proportions and body composition in adult women with Ullrich-Turner syndrome. Am J Med Genet. 72:403- 408. 